\title{
Discussion on the Influencing Factors of Hainan Rural Tourism Development
}

\author{
Lv Jieru \\ Hainan College of Foreign Studies, Wenchang, China
}

Keywords: Hainan; rural tourism; development; influencing factors

\begin{abstract}
With the continuous improvement of living standards, the continuous development of urbanization and the pace of life is faster and faster, people in the city are more and more yearning for rural idyllic life. Therefore, rural tourism is increasingly welcomed by urban residents and has maintained good development prospects in recent years. With its natural conditions and geographical advantages, Hainan Province began to develop into rural tourism after going through the competition of scenic spots and lines, and stepped into the era of rural tourism competition. Based on the actual status and development advantages of the development of rural tourism in Hainan, this paper analyzes the problems existing in the development of rural areas in Hainan and the factors that influence them.
\end{abstract}

\section{Introduction}

The development of rural tourism in Hainan is very good. The starting time is late but the development is very rapid. In the course of development in recent years, Hainan Province has enabled a large number of tourists to come here to experience Hainan's local customs and experience the ecological environment of Hainan because of the unique geographical advantages, geographical advantages, and differences in ethnic cultures. However, there will be some problems in the development of any industry, such as tourism planning, facilities construction and so on.

\section{The Present Status of Rural Tourism Development in Hainan}

Surrounding Hainan Province, it is a village with a beautiful natural environment, a strong original atmosphere, and a different ethnic culture. With the promotion of the current social background, more and more people have longed for it and become a popular place for people to enjoy. With the development of tourism in Hainan, Hainan rural tourism has a very good development prospect in this context. Although Hainan's rural tourism started relatively late, but Hainan's tourist resort has been a support and it has developed very rapidly. Although the development of rural tourism in Hainan is fast, from the national scope analysis, there is no real mature rural tourism market. The main source of tourists is Hainan Island residents, mainly concentrated in Haikou, Sanya and other cities and counties, the consumption level is limited. The scale of tourism is small, mainly in the form of farm food and farmhouse-style housing, and lacks superior tourism products for rural holiday experiences.

Most of the rural tourism in Hainan is concentrated in the suburbs of the city. There is no excessive investment in infrastructure, resulting in a lack of rural tourism infrastructure, poor accommodation and meals, and no basic medical facilities as support. Therefore, the comprehensive service functions are relatively insufficient. The development of Hainan's rural tourism mainly depends on the natural scenery of Hainan Province, and it does not focus on the unique local customs resources. It is still based on the form of "agritainment". In the current tourism industry in Hainan, there are too few recreational and personalized tourism projects, and the activities are simple. This reduces the expectations of tourists for rural tourism. The development of rural tourism in Hainan is relatively late, and professionals engaged in rural tourism in Hainan are insufficient, the corresponding institutions are not perfect, the quality of service is not up to standard, and the propaganda methods of operators are also relatively single, and they have not paid enough attention to propaganda and lack of initiative. The popularity is not recognized by everyone and hinders the 
development of tourism in Hainan's rural areas.

\section{Development Advantages}

\subsection{Natural ecological environment}

Hainan Province is known as China's tropical garden, and the resources for rural tourism are rich and colorful. Its unique climate and rich ethnic culture have created a colorful rural environment. There are coastal villages, mountainous villages and plain villages, which make Hainan's rural tourism more distinctive.

\subsection{Unique ethnic customs}

There are many different ethnic groups in Hainan, making Hainan have different regional features. The islanders on the island have developed a unique national culture in the development of thousands of years, and they have their own unique ways of clothing and eating.

\subsection{The construction of ecological civilization is up to the standard}

From a long time ago, Hainan created a civilized new village with the theme of building an ecological environment, which has greatly changed the environment and style of the villages. Its infrastructure and peasants' literacy have been improved, and the harmonious development between man and nature has been promoted, laying the foundation for Hainan's rural tourism industry.

\section{The Mode of Rural Tourism Development in Hainan}

\subsection{Idyllic sightseeing}

Hainan rural tourism mainly consists of green tourism spots and pastoral tourism. It is more traditional in terms of patterns. Visitors can visit unique agricultural productions, taste local food, and experience rural life. In the rural tourism industry in Hainan, the pastoral sightseeing-style model is taken as the principal thing and there are a lot of tourists, and communication methods need to be discussed with the travel agency to increase the flow of people.

\subsection{Recreation \& Entertainment}

The development of this model is mainly supported by beautiful natural scenery. Building country villas or high-grade resort facilities, opening up to high-income groups, and providing them with comprehensive services for leisure and vacation. This is mainly distributed in rural areas near Haikou and Sanya cities. The market is stable and conducive to the development of the tourism industry.

\subsection{Ethnic minority style}

In Hainan, there are many ethnic minorities, and the rural ethnic customs is the main mode, its distribution is mainly in the mountains and countryside, which providing visitors with unique features of the diet and entertainment.

\subsection{Ancient town}

Tourist activities based on ancient towns are more attractive to tourists in terms of cultural value and tourism value. The government has played a very important role in regulating tourism development in ancient towns. For the unique historical and cultural town, it needs to be well protected to attract more tourists with a strong historical culture. 


\section{Factors Affecting the Development of Rural Tourism in Hainan}

\subsection{A graphic display of factors affecting rural tourism in Hainan}

\begin{tabular}{|l|l|l|}
\hline Category & Main content & Influencing factors \\
\hline $\begin{array}{l}\text { Production } \\
\text { conditions }\end{array}$ & $\begin{array}{l}\text { Mainly refers to the geographical location of } \\
\text { the industry resources, climate, } \\
\text { communication facilities, research } \\
\text { institutions, etc. }\end{array}$ & $\begin{array}{l}\text { Geographical location, tourism resources, } \\
\text { product facilities }\end{array}$ \\
\hline Requirement & Scale, structure, and growth & Domestic and overseas markets \\
\hline Industry support & Can provide support for the industry & $\begin{array}{l}\text { Catering, accommodation, transportation, } \\
\text { entertainment }\end{array}$ \\
\hline competition & The goal and trend of Industrial Development & $\begin{array}{l}\text { Comparison of competition conditions } \\
\text { and differentiation }\end{array}$ \\
\hline $\begin{array}{l}\text { Development } \\
\text { opportunities }\end{array}$ & Important events to promote development & Hainan establishes international tourism \\
\hline $\begin{array}{l}\text { Governmental } \\
\text { support }\end{array}$ & $\begin{array}{l}\text { Impact through planning, management, and } \\
\text { promotion }\end{array}$ & Financial support, tourism marketing \\
\hline
\end{tabular}

\subsection{Farmers have low levels of education}

Farmers are the main support for rural tourism construction. The cultural quality of farmers directly determines the development of rural tourism. In Hainan, some rural areas have been affected by social and economic development for a long time, so that the education level of farmers is generally low. The lack of culture among the peasant masses has made it impossible for traditional industries to pass on, and the innovation of rural culture is even more worrying. The lack of knowledge has brought many problems to rural culture. It will make the peasants' thoughts lag behind, and they will not take the initiative to change their consciousness of the development of the status quo. The concept of thinking is conservative and backward.

\subsection{Lack of innovation}

The current development characteristics of rural tourism are mainly based on agriculture and holiday, lack of national culture, and there is no effective integration with local characteristics. In the tourism industry in Hainan Province, the problem of product assimilation is very serious. Lacking of local cultural feelings, tourism products cannot meet the needs of tourists. Many tourist attractions are for profit and lack of innovation in the types of products. Many tourism products are similar, making tourists feel monotonous and have a psychological repulsion, which is very detrimental to the development of rural tourism.

\subsection{The incomplete tourism industry}

Hainan has the characteristics of geographical advantages, the development of the industry is also very complete, and transportation facilities are also very convenient, extending to all townships and tourist attractions, but due to the lack of a well-established transportation system in the countryside, the interaction is not comprehensive, and communication, network facilities and entertainment in the scenic spots are in urgent need of improvement.

\subsection{Government's support}

The government's support for the tourism industry will directly affect the direction and scale of tourism development in a region. Rural tourism will encounter problems in capital and technology during the development process. If the government gives policy support, it can effectively solve the development problems in a region. Analysis from other angles can protect the environment and promote long-term economic development. In recent years, the development of Hainan's tourism industry has seen many problems in the market. It requires the government to make timely adjustments, formulate corresponding laws and regulations, and standardize the tourism market. 


\section{A Strategic Analysis of the Influencing Factors of Rural Tourism in Hainan}

\subsection{Innovate in tourism products}

The development of rural tourism in Hainan Province requires diversified tourism products. Therefore, innovation and design of tourism products are directly related to the long-term development of rural tourism products. When innovating, we should first optimize the product structure and strengthen the content and quality of services. In the current development process of rural tourism, the biggest problem encountered is that tourism products are single, of low quality and of small variety. Tourism products are the focus of tourists' travel and relate to the future of rural tourism development. A single product cannot meet the differentiated needs of tourists. We should increase the development of tourism, develop products suitable for local culture, develop additional types of tourism products, increase visitor volume and attention, and then increase the return rate. On the other hand, the start of rural tourism products is late, people's understanding of rural tourism is still only on the surface, making the development of rural tourism limited. While, the low grade, poor quality, and poor service of rural tourism products hinder the overall development of rural tourism. Combining the local ethnic culture and geographical advantages of Hainan Province, we should develop tourist products with local characteristics, such as hand sightseeing and tourist attractions. Using beautiful rural scenery as a tourist attraction to develop natural and intimate tourism projects and attract city residents for sightseeing. Another example is the national culture type. According to Hainan's folk culture and landscape, we provide unique dining and entertainment activities to provide visitors with opportunities to understand Hainan's folk customs and culture, to give full play to local resource advantages and build rural tourism brands, realizing the sustainable long-term development of the rural tourism industry.

\subsection{The overall promotion of tourism image}

The tourist image is very important for tourists when choosing a place for tourism. The distinctive tourism image can make it easier for people to distinguish the difference in tourism, and can effectively guide the consumption of tourists and promote the development of tourism products. As far as the current status of tourism development is concerned, the tourism industry attaches great importance to the design of tourism destination images. This is the image of tourism and it is a good guarantee for improving economic development. Using advertising or marketing methods to promote all-round promotion of rural tourism in Hainan, so that more people understand the unique culture here, make the media or the public on behalf of the task to experience the characteristics of rural tourism and then propagate, which will arise the public's attention and enabled Hainan's rural tourism image to be effectively promoted.

\subsection{Improve the infrastructure of rural tourism industry}

Hainan Province is building an ecologically-civilized village, and the current status of tourism needs to be further strengthened. The current rural infrastructure is temporarily unable to meet the development requirements of rural tourism. In the process of construction, we should improve the rural tourism facilities and transportation facilities in Hainan, increase capital investment, and improve transportation, hydropower and communications equipment. In addition, we should build rural tourism special line to facilitate the majority of tourists choose tourist attractions, improve the public health and tourism indications, improve the health standards and service quality, so that the majority of tourists feel comfortable eating and peace of mind.

\section{Conclusion}

Taking Hainan rural tourism as its mainstay, its unique geographical environment and national culture are all important ways to promote rural tourism in Hainan and promote the development of the tourism industry. The rapid development of rural tourism is the tourism industry resulting from changes in this era. People live in a fast-paced city where people are busy, so that modern people are still under pressure from the work and under the pressure of the city. Therefore, relax yourself, 
slow down and feel the taste of life, feel the breath of nature, and experience the original pleasure. The rural tourism industry grows rapidly in such an environment. Therefore, vigorously developing rural tourism is the need of this era and is one of the important ways for people to relax their lives.

\section{References}

[1]Zhuyu Wang, Shuen Wang. An Analysis of the Mechanism and Countermeasures of Hainan Rural Tourism Promoting the Innovation of Agriculture, Countryside and Farmers [J]. Bulletin of Science and Technology, 2016, 32(9):77-81.

[2] Liqun Chen. Research on Development Status and Optimization Strategies of Rural Tourism in Hainan Province [J]. Chinese Journal of Agricultural Resources and Regional Planning, 2016, 37(10):206-211.

[3] Cailian Bao. Research on the Status Quo and Countermeasures of Hainan Rural Tourism Development [J]. The Border Economy and Culture, 2015(1):5-6.

[4] Changqing Lin. Research on Current Situation, Countermeasures and Prospect of Rural Tourism in Hainan [J]. Rural Economy and Science-Technology, 2016, 37(6):67-68.

[5] Cuiping Zhao. Study on the Development of Rural Tourism in Hainan under the Background of Universal Tourism [J]. Cultural Geography, 2017(16).

[6]Qingrong Xiong. Analysis on Key Factors Affecting Hainan Rural Tourism Destination Competitiveness [J]. Market Modernization, 2015(10):154-155. 